\title{
Abundance and morphology of microplastics in an agricultural soil following long-term repeated application of pig manure
}

\author{
Jie Yang ${ }^{\text {a, c }}$, Ruijie Li ${ }^{\text {b, c }}$, Qian Zhou ${ }^{\text {b, c }}$, Lianzhen $\mathrm{Li}^{\mathrm{b}}$, Yuan Li ${ }^{\mathrm{b}}$, Chen Tu ${ }^{\mathrm{b}}$, Xinyue Zhao ${ }^{\mathrm{b}}$, \\ Kuanxu Xiong ${ }^{\mathrm{b}}$, Peter Christie ${ }^{\mathrm{a}}$, Yongming Luo ${ }^{\mathrm{a}, \mathrm{b}, *}$ \\ a CAS Key Laboratory of Soil Environment and Pollution Remediation, Institute of Soil Science, Chinese Academy of Sciences, Nanjing, 210008, China \\ ${ }^{\mathrm{b}}$ CAS Key Laboratory of Coastal Zone Environmental Processes and Ecological Remediation, Yantai Institute of Coastal Zone Research, Chinese Academy of \\ Sciences, Yantai, 264003, China \\ ${ }^{\mathrm{c}}$ University of the Chinese Academy of Sciences, Beijing, 100049, China
}

\section{A R T I C L E I N F O}

\section{Article history:}

Received 3 August 2020

Received in revised form

4 November 2020

Accepted 5 November 2020

Available online 9 November 2020

\section{Keywords:}

Accumulation

Farmland soil

Long-term fertilization

Microplastics

Morphology

Pig manure

\begin{abstract}
A B S T R A C T
Microplastics occur widely in the terrestrial environment and they currently occur in organic fertilizers applied to agricultural land. However, there is little information available on the accumulation of microplastics in soils fertilized over the long term. Here, we investigate the characteristics of microplastics in both pig manure and soil following long-term manure application in an attempt to assess their accumulation and the potential risk to agricultural soils of repeated application of pig manure. Microplastics were separated from soil and pig manure samples using a sequential flow separation and flotation method. The abundances of microplastics were $16.4 \pm 2.7$ and $43.8 \pm 16.2$ particles $\mathrm{kg}^{-1}$ in control plots (CK, no manure applied) and plots amended annually with pig manure for 22 years (PM), respectively. The microplastics (especially fragments) were significantly enriched in PM-amended soil compared with the control plots. The average annual abundance of microplastics was $1250 \pm 640$ particles $\mathrm{kg}^{-1}$ in manure. Interestingly, the type and polymer composition of microplastics were very similar in the soil and manure. Differences in color and particle size indicate that microplastics sourced from pig manure may be gradually weathered and degraded after incorporation into the soil. The average accumulation rate of microplastics in the agricultural soil with long-term application of pig manure was estimated to be $3.50 \pm 1.71$ million particles $\mathrm{ha}^{-1} \mathrm{a}^{-1}$. The microplastics in the manured soil displayed complicated weathered surfaces. The presence of carbonyl groups suggests that the weathered microplastics in soil may have the potential to adsorb contaminants.
\end{abstract}

(c) 2020 Elsevier Ltd. All rights reserved.

\section{Introduction}

The widespread occurrence of microplastics in terrestrial ecosystems is of great public concern. The amount of plastics released annually to soils has been estimated to be 4-23 times higher than that released to the oceans (Horton et al., 2017). Agricultural ecosystems are especially likely to be contaminated with microplastics because of the multiple sources of plastics used in agricultural practice (Ng et al., 2018). The application of sewage sludges in agriculture is one example because most of the microplastics

\footnotetext{
* This paper has been recommended for acceptance by Eddy Y. Zeng.

* Corresponding author. CAS Key Laboratory of Soil Environment and Pollution Remediation, Institute of Soil Science, Chinese Academy of Sciences, Nanjing, 210008, China.

E-mail address: ymluo@issas.ac.cn (Y. Luo).
}

present are retained in sludges after sewage treatment. Repeated application of sludge to agricultural land inevitably results in the accumulation of microplastics in the soil (Li et al., 2018; Berg et al., 2020). The abundance of microplastics in agricultural soil was up to 600-10,400 particles $\mathrm{kg}^{-1}$ and increased with increasing frequency of application in Chile (Corradini et al., 2019). Widely-used plastic mulch films are also an important source of microplastics in agricultural soils (Huang et al., 2020) and the residual film can be further fragmented into microplastics. For example, agricultural soils on the coastal plain of Hangzhou Bay in east China showed a higher average abundance of microplastics in the surface of mulched soils than in non-mulched soils with 571 and 263 particles $\mathrm{kg}^{-1}$, respectively (Zhou et al., 2020). In general, microplastics in agriculture are mainly derived from biosolids, organic manures, polyethylene mulching films, atmospheric deposition, irrigation, and surface runoff (Luo et al., 2018). However, little is known about 
the accumulation of microplastics in organic soils receiving repeated applications of organic manures.

Organic manures are important sources of plant nutrients in agricultural production and they can also improve and maintain soil quality (Ro et al., 2016; Karimi et al., 2018). Furthermore, longterm manure application increases the abundance of bacteria, fungi, and other microorganisms (Wang et al., 2020). However, repeated application of organic manures can result in soil pollution with potentially toxic elements and antibiotic residues (Guo et al., 2018). The (micro)plastic pollution of organic fertilizers has usually been ignored. Gajst (2016) found up to $1200 \mathrm{mg}$ plastics $\mathrm{kg}^{-1}$ in organic compost in Slovenia. Bläsing and Amelung (2018) estimated that the amount of visible plastic discharged into farmland with an annual application of compost would be $0.016-1.2 \mathrm{~kg} \mathrm{ha}^{-1}$ (based on an annual rate of compost application of $7 \mathrm{t} \mathrm{ha}^{-1}$ ). Surprisingly, most countries allow the application of plastics in organic fertilizers which are allowed to contain $0.1 \mathrm{wt} \%$ of plastics in Germany, one of the countries with the most stringent quality control of organic fertilizers (Weithmann et al., 2018). Microplastics may be more abundant than plastics in organic fertilizers. The source of the (micro)plastics in manure may be feces and the surrounding environment during the composting process. Previous studies show that microplastics occur in animal and human feces (Yan et al., 2020). In addition, microplastics can be transported in air and deposition in outdoor and indoor environments (Enyoh et al., 2019). Evaluation of the impact of the application of organic fertilizers on the accumulation of microplastics in agricultural land is therefore urgently required.

Here, we investigate the abundance, distribution, and morphology of microplastics in 'red soil' (Acrisols according to the FAO classification system) with repeated application of pig manure.
The aim is to understand the accumulation and surface weathering of microplastics in agricultural land following long-term repeated application of pig manure.

\section{Materials and methods}

\subsection{Site description and sample collection}

The long-term field plots were established in 1996 at the National Agricultural Ecosystem Observation and Research Station at Yingtan, Jiangxi province, southeast China $\left(28^{\circ} 12^{\prime} \mathrm{N}, 116^{\circ} 55^{\prime} \mathrm{E}\right.$; Fig. 1). The test soil is derived from Quaternary red clay. The experiment contained control plots ( $\mathrm{CK}$, no fertilizer applied) and experimental plots to which pig manure was applied annually for 22 years (PM). The pig manure was obtained from a nearby pig farm and was applied annually at a rate of $1.69 \mathrm{t} \mathrm{ha}^{-1}$ (dry weight basis) before planting peanut. Conventional field management was carried out during the growing period.

Soil samples were collected on July 22, 2018 to a depth of $\sim 20 \mathrm{~cm}$ using a steel soil sampler and roots and stones were removed. Duplicate samples were collected from randomized plots of each treatment (CK, 2 plots; manure amended soil, 10 plots). Each sample was taken randomly using a multipoint mixed method. The soil samples were homogenized in the laboratory to avoid crosscontamination. Soil Moisture content was calculated by the ovendrying method (Zhou et al., 2018) (Table S1 in Supplementary data).

\subsection{Separation of microplastics}

A microplastic separation method was established based on a continuous air-flow flotation separation device (Zhou et al., 2018).

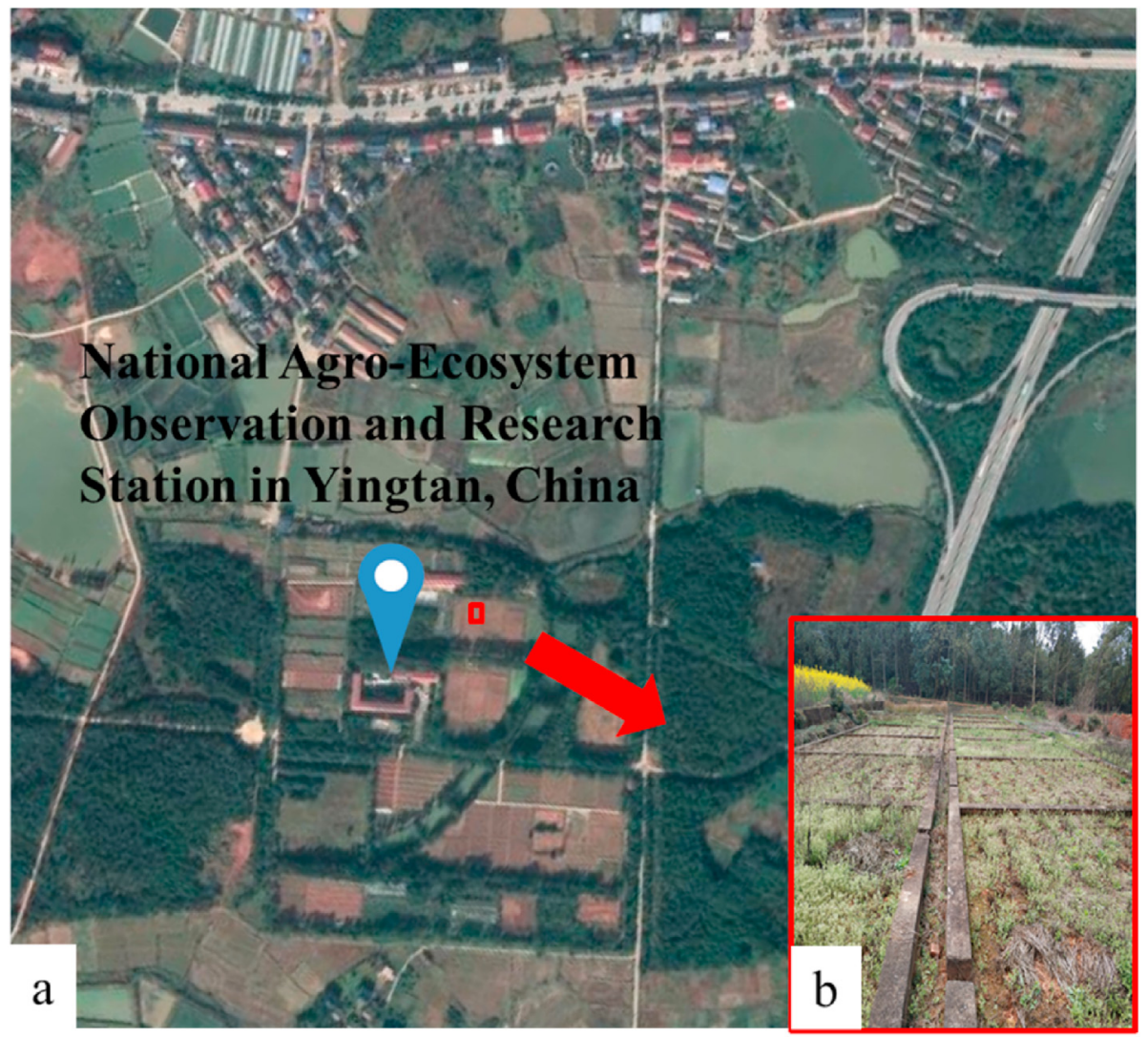

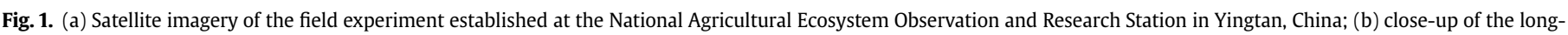
term manure application field. 
A vacuum filter pump was used instead of wet sieve filtration to save time and avoid the loss of microplastics during transfer that can occur using the traditional flotation method. The soil samples ( $250 \mathrm{~g}$ ) were weighed into dry glass beakers. Saturated $\mathrm{NaCl}$ solution $\left(\rho 1.20 \mathrm{~g} \mathrm{~cm}^{-3}\right)$ was added and the suspensions were stirred and shaken using ultrasound for $5 \mathrm{~min}$. Large clods of soil were crushed using a glass rod to mix and disperse the soil thoroughly. After density separation, the residues were further floated using a saturated Nal solution $\left(\rho 1.60 \mathrm{~g} \mathrm{~cm}^{-3}\right.$ ) if they contained many solid particles. Finally, the sample filtered with a $20-\mu \mathrm{m}$ pore nylon fiber membrane (Millipore, Burlington, MA), washed with $30 \% \mathrm{H}_{2} \mathrm{O}_{2}$ to dissolve the organic matter on the electric hotplate $\left(72 \mathrm{~h}, 60{ }^{\circ} \mathrm{C}\right)$. The samples were observed after filtration.

The same separation method was used for dried pig manure samples collected from 2011 to 2018 (2014-2016 samples were unavailable or contaminated). Due to the small amount of stored pig manure samples, duplicate 5-g manure samples were weighed into dry glass beakers. The pig manure did not contain solid soil particles and secondary flotation in saturated NaI solution was not required. There were more residues in the manure than in the soil. Particular care was taken to pick out suspected microplastic particles using microscopic observation.

\subsection{Microplastic identification and analysis}

Macroplastics ( $>5 \mathrm{~mm}$ ) were excluded from the study. Microplastics were counted and measured after flotation using a stereomicroscope (Model S9i, Leica AG, Wetzlar, Germany). Microplastics (2-5 mm, not including fibers) were identified using Fourier transform infrared spectrometry (Nicolet iS10, Thermo Fisher, Waltham, MA) fitted with an ATR accessory (ATR-FTIR). The spectral range was $650-4000 \mathrm{~cm}^{-1}$ at 32 scans. Representative particles $(<2 \mathrm{~mm})$ and fibers were identified by $\mu$-FTIR (Nicolet iN10, Thermo Fisher, Waltham, MA). The spectral range was set at $650-4000 \mathrm{~cm}^{-1}$ and samples were scanned 16 times. A scanning electron microscope (SEM) (s-4800, Hitachi, Tokyo, Japan) was used to observe the surface morphology of the microplastics, and the elemental composition of selected surface micro-domains was analyzed by combination with an energy dispersive spectrometer (EX-350, Horiba, Kyoto, Japan).

The microplastics were classified into four categories based on their characteristics and morphology, namely fibers (elongated strings), fragments (hard angular pieces), films (soft transparent flakes), and granules (irregular stereo particles) (Fig. S1). Here, the category polypropylene comprised poly(ethylene)propylene copolymers, polyethylene consisted of low-density and high-density polyethylene, and polyester (PES) encompassed polyester fibers and polyethylene terephthalate (PET).

\subsection{Statistical analysis}

Microplastics were counted according to color, size, composition, and type. The abundance of microplastics in the soil and manure samples was expressed as particles $\mathrm{kg}^{-1}$ dry weight. The data are shown as mean \pm standard deviation and were recorded and drawn using Microsoft Excel 2016 and OriginPro 2017. The data were subjected to analysis of variance and independent sample $t$ test using the SPSS 18.0 software package and differences at $p<0.05$ were considered to be statistically significant.

\subsection{Quality assurance $(Q A)$ and quality control $(Q C)$}

Separation and extraction of microplastics were conducted in a laboratory without cross-contamination. Deionized water and dustproof clothing were used in all experiments to avoid cross- contamination throughout the process. Two procedural blanks were set up for soil and manure samples. Occasional cotton fibers were found in the soil blanks and three polyester fibers were observed in the manure blanks. Results were corrected by subtracting background values (Table S2 and Table S4 in the Supplementary data).

A recovery experiment was set up using triplicates based on the procedures described in section 2.2 above. Representative microplastics were chosen to include analytical grade polymers (polyamide (PA), polypropylene (PP), polystyrene (PS), polyethylene (PE), polyvinyl chloride (PVC), expandable polystyrene (EPS)), PA fiber, and PE film. The average recoveries ranged from 81.7 to $100 \%$, with PA fiber giving the lowest recoveries (Table S3 in the Supplementary data).

\section{Results and discussion}

\subsection{Characteristics and accumulation of microplastics in the soil} with repeated applications of pig manure

Microplastics were detected in all soil samples examined and transparent microplastics accounted for a larger percentage $(72.8 \%)$ in manured (PM) than in control plots (50.0\%) (Fig. 2 (a)). Lv et al. (2019) found that white, translucent, and black were the dominant colors of microplastics in rice-fish co-culture system soils in Shanghai, China. Another investigation found that white microplastics (62.5\%) predominated in agricultural land in southeast Germany (Piehl et al., 2018). Thus, the color of microplastics in different areas and different soil uses are not consistent. Microplastics $<1 \mathrm{~mm}$ accounted for 50.0 and $54.4 \%$, respectively, in the control and manured plots (Fig. 2 (b)). The abundance of microplastics in the soil was inversely proportional to particle size and this agrees with previous studies (Liu et al., 2018; Zhou et al., 2018). Microplastics with smaller particle sizes $(<1 \mathrm{~mm})$ might be more readily ingested by soil organisms (Lwanga et al., 2016). A study of vegetable fields in suburban Wuhan in central China found that $95 \%$ of the microplastics were $1 \mathrm{~mm}$ (Chen et al., 2020). Zhang and Liu (2018) also found that $95 \%$ of the microplastics in an arable soil near Dian Lake in southwest China were $<1 \mathrm{~mm}$.

Four microplastic polymers were detected after excluding cotton and other organic substances (such as sorbitan monooleate and polygalacturonic acid sodium) from the extracted fibers and particles. These were polyester (PES), polyethylene (PE), polypropylene (PP), and rayon (Fig. S2). The percentages of microplastic polymers in the manured soil (high to low) followed the sequence PP (47.8\%), PES (39.1\%), rayon (7.07\%), and PE (5.98\%). PES, PP, and rayon also occurred in the controls (Fig. 2(c)). Rayon fibers are common in agricultural land and coastal mangrove sediments (Zhou et al., 2020a; 2020b). PP (50.5\%), PE (43.4\%), and PES (5.91\%) occurred in a vegetable soil covered by agricultural mulching film (Liu et al., 2018). Microplastics in traditional agricultural soils also consist of polyethylene and polypropylene (Piehl et al., 2018). These microplastic types may be derived from the degradation of large pieces of conventional plastics contaminating the environment.

The abundance of microplastics was significantly different in the control and manured samples (Fig. 2(d)), with $16.4 \pm 2.7$ and $43.8 \pm 16.2$ particles $\mathrm{kg}^{-1}$, respectively. Moreover, only fibers were present in control samples and the abundance of fragments in manured samples was significantly higher than in the controls. The experimental area is remote from residential areas and relatively unaffected by urban activities. This indicates that repeated applications of pig manure had significantly increased the abundance of soil microplastics. Here, the surface soil was sampled to a depth of $20 \mathrm{~cm}$ to better reflect the level of accumulation of microplastics in this cultivated soil. The abundance of microplastics was low 

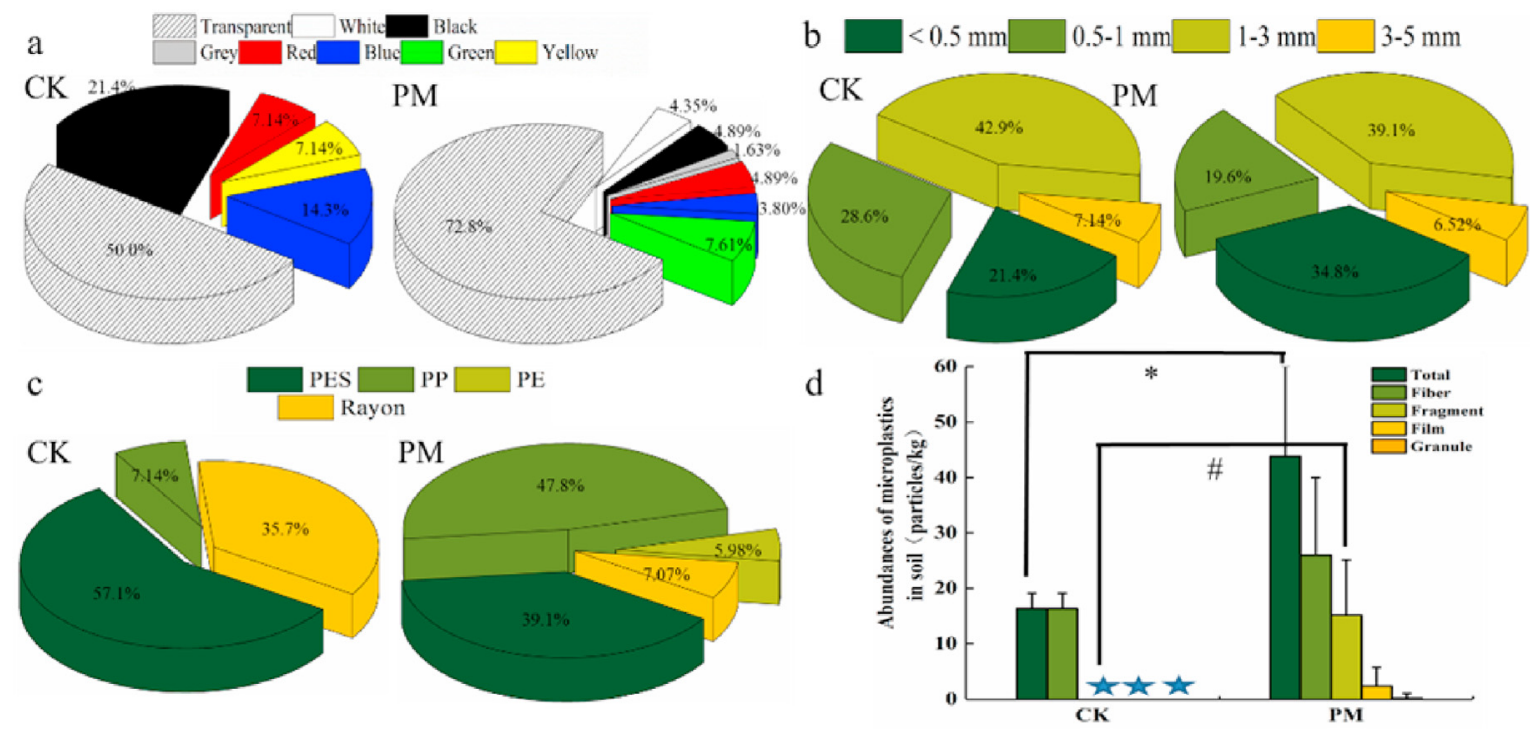

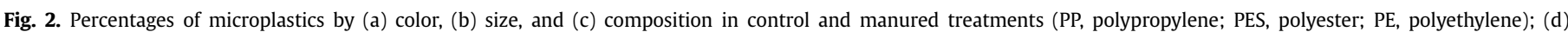

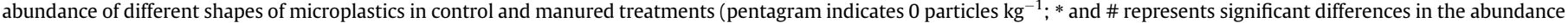

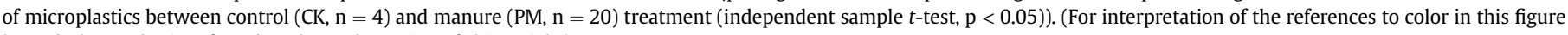
legend, the reader is referred to the Web version of this article.)

compared with other studies, perhaps due to the distance from residential areas or the relatively deep sampling. The abundance of microplastics in soil can be negatively related to sampling depth (Xu et al., 2019). The abundance of microplastics at depths $0-3 \mathrm{~cm}$ and $3-6 \mathrm{~cm}$ in an agricultural soil in suburban Shanghai was $84.8 \pm 13.2$ and $66.0 \pm 13.9$ particles $\mathrm{kg}^{-1}$ dry soil (Liu et al., 2018). Piehl et al. (2018) found that the abundance of microplastics at a depth of $5 \mathrm{~cm}$ in agricultural land where only traditional agricultural methods were practiced was $0.34 \pm 0.36 \mathrm{~kg}^{-1}$. Human activities have a distinct impact on the abundance of microplastic in soils. The use of agricultural films or fertilizers will increase the abundance of microplastics in agricultural land.

Here, the average accumulation of microplastics in agricultural land via pig manure was estimated to be $1.25 \pm 0.61$ particles $\mathrm{kg}^{-1} \mathrm{a}^{-1}$. The soil bulk density at the experimental site is calculated at $1.40 \mathrm{~g} \mathrm{~cm}^{-3}$ (without regard to the effect of manure applications). The average accumulated amount of microplastics in the surface soil under repeated applications of pig manure may reach $3.50 \pm 1.71$ million particles ha $\mathrm{a}^{-1} \mathrm{a}^{-1}$. This indicates that the organic manure is an important source of soil microplastics and is similar to the accumulation of soil microplastics from repeated applications of sewage sludge. Previous studies report that the abundance of microplastics accumulated in a Chilean soil with application of sludge ranged from 1100 to 3500 particles $\mathrm{kg}^{-1}$ (Corradini et al., 2019). One recent study found that the abundance of microplastics in soil was 545.9 and 87.6 particles $\mathrm{kg}^{-1}$ after repeated application of sludge compost (30 and $15 \mathrm{t} \mathrm{ha}^{-1} \mathrm{a}^{-1}$, respectively), values significantly higher than in the unamended soil ( 5 particles $\mathrm{kg}^{-1}$ ) (Zhang et al., 2020). Very large application rates of sludge containing numerous microplastics will result in the accumulation of microplastics in the soil.

\subsection{Surface morphology and attachments of microplastics in the soil with repeated application of pig manure}

The surface morphology of microplastics in this soil is shown in Fig. S3. Our observations indicate that microplastics show complicated morphological features after long-term weathering in the soil. Fibers and granules exhibited protrusions and depressions on the surfaces. The surfaces of the fragments exhibited some cracks and several filaments around the cracks. In addition, there were large micropores $(\sim 1 \mu \mathrm{m})$ on the surfaces of the thin films (Fig. S3 (f, i)). The surface features differ from previous studies in which strong weathering influences on microplastic surfaces were observed in coastal beach soils (Cooper et al., 2010; Zhou et al., 2018). Strongly weathered microplastics indicate that the morphologies are related to mechanical, chemical, and biological processes (Zhou et al., 2018; 2020b). The arable soil in this area may be less subject to abiotic degradation (such as UV radiation and mechanical erosion) due to the soil depth and vegetation cover. Some very small micropores and filaments in fragments and films may reflect the important role of microorganisms. Microorganisms can colonize the surfaces of films in soils (Huang et al., 2020). Zhang (2019a) also found numerous microbes inhabiting micropores on the surface of a mulching film. Microplastics have the potential to attract degradative microorganisms. It is important to conduct further research to determine whether or not organic manures lead to the formation of secondary microplastics in soils.

Elemental analysis of the surfaces of the fragments and thin films is shown in Fig. 3. The surfaces of the microplastics contained $\mathrm{Si}, \mathrm{Al}, \mathrm{Fe}, \mathrm{Mg}$, and other elements present in the environment as oxides. Soil mineral colloids presumably exist on the surfaces of microplastics. Jian et al. (2018) also found clay minerals attached to the surfaces of microplastics in the bottom mud of Poyang Lake. This indicates that plastic-mineral complexes occur widely in the environment. PP fragments and PE films from the long-term manured soil were analyzed by ATR-FTIR and compared with commercial PP woven bags and PE film (Fig. 4). Interestingly, peaking at $1034 \mathrm{~cm}^{-1}$ was likely due to clay on the surfaces. This is consistent with the aging results of PE film in the soil of Briassoulis et al. (2015). Moreover, the hydroxyl and carbonyl absorption peaks of microplastics in the environment occur around 3450 and $1700 \mathrm{~cm}^{-1}$, respectively. This suggests that the microplastic surface generates functional groups such as carboxyl, aldehyde, and hydroxyl (Fairbrother et al., 2019). The appearance of these functional groups was related to the degradation of microplastics. Microplastics may thus act as carriers to adsorb pollutants, making it easier to transfer contaminants and cause harm (Xu et al., 2019). 

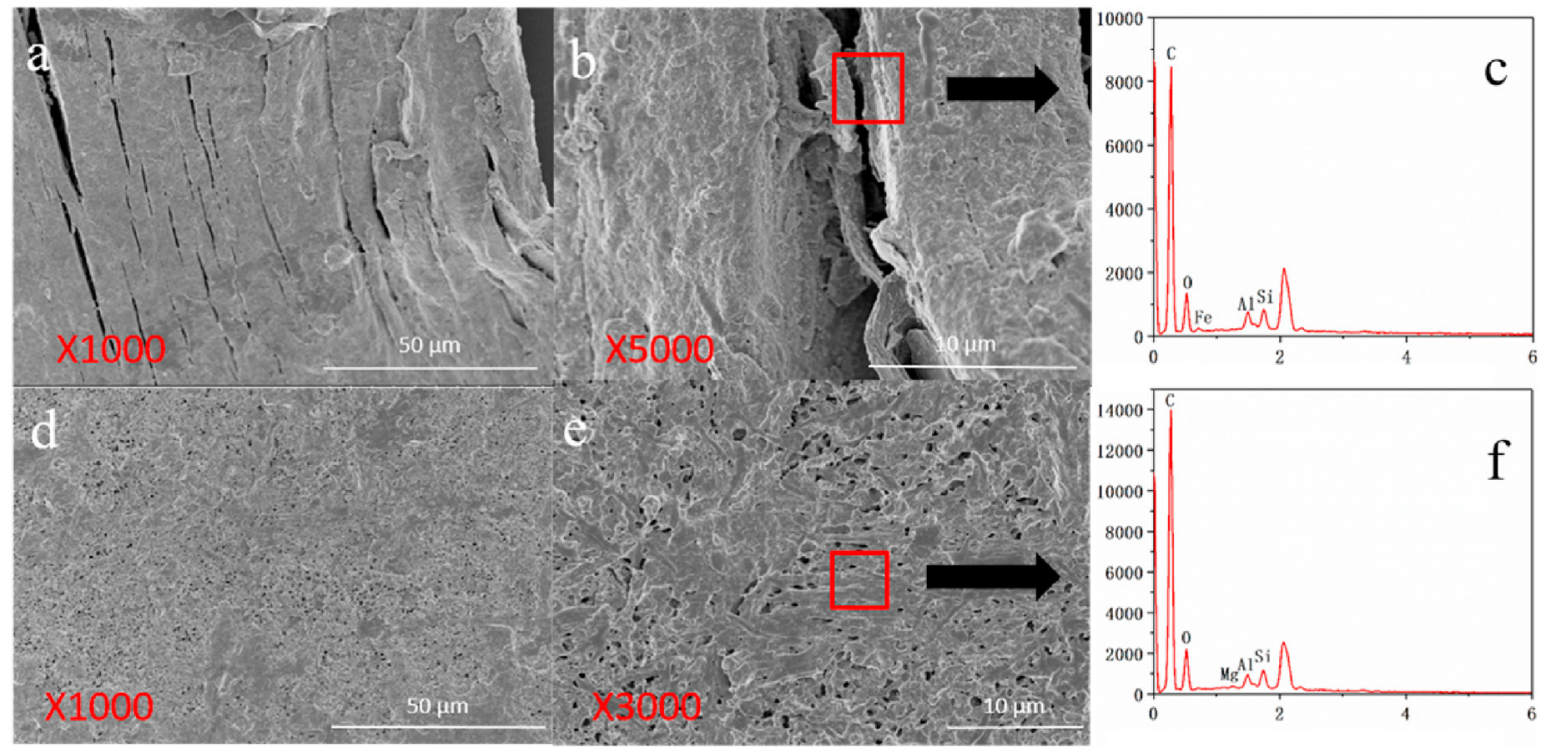

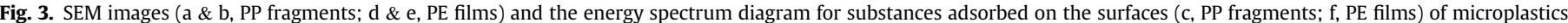
from the long-term manured soil.

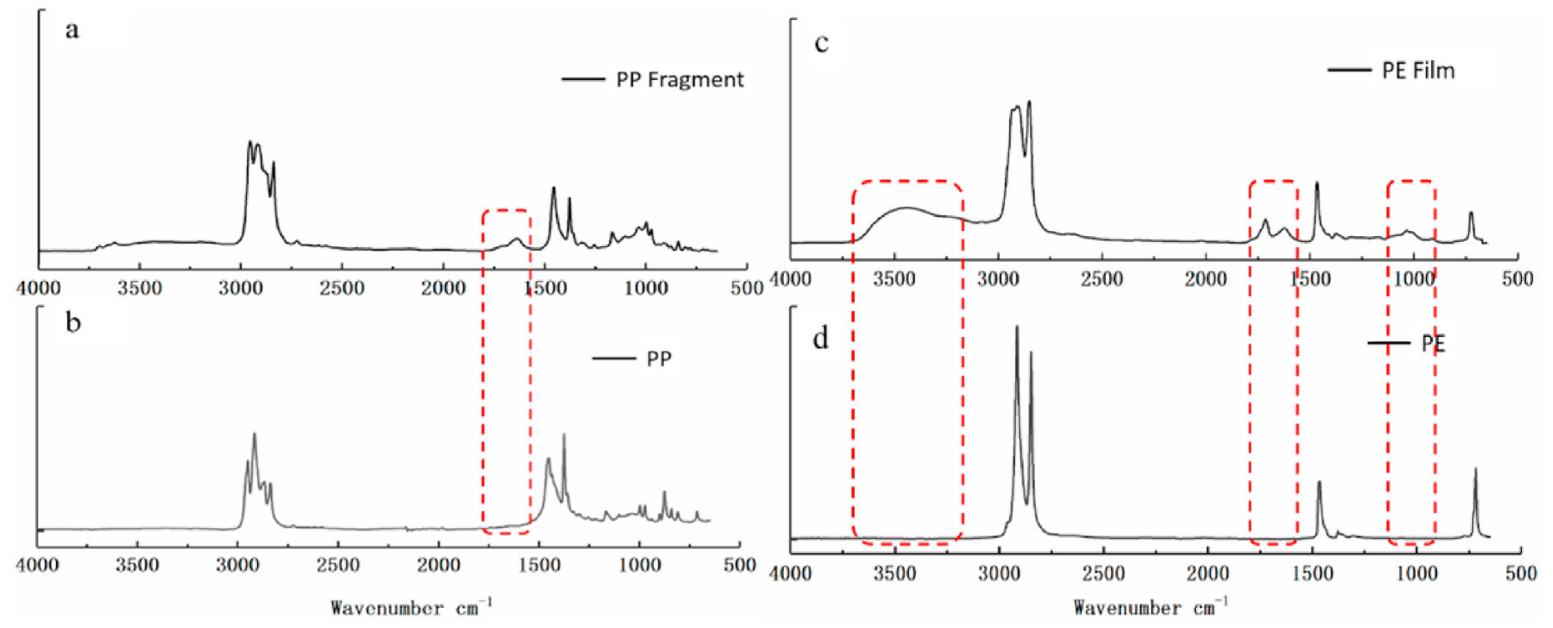

Fig. 4. Comparation of (a, b) PP fragments and (c, d) PE films from the soil with those of commercial substances by ATR-FTIR spectra.

Degraded microplastics also release more harmful additives (Bandow et al., 2017).

\subsection{Characteristics of microplastics in pig manure and their contribution to microplastic accumulation in the soil}

Aggravated pollution by microplastics in agricultural land from the application of pig manure was further explored. The distribution of microplastics in pig manure in different years was examined. Microplastics occurred in all manure samples examined (Fig. 5, Table S4). Fig. S4 shows photos of typical microplastics that have been extracted from pig manure. Classification by color, size, and composition (Fig. 5(a, b, c); Fig. S5) gives detailed information on the manures in different years. A total of seven colors of microplastics were found, with black (32.8\%) and blue (27.2\%) predominant (transparent $12.8 \%$, red $12.8 \%$, white $11.2 \%$, green $1.60 \%$, purple $1.60 \%$ ). Microplastics in pig manure had a wider range of colors than those in manured soil. The average percentage of microplastics $>1 \mathrm{~mm}$ in manure was $63.2 \%$ and was higher than in the experimental soil. These results indicate that microplastics can be broken down and undergo abiotic and biotic degradation in the soil. Feuilloley et al. (2005) found PE plastic film breaking down into smaller plastics in the natural environment. The composition of microplastics from pig manure was similar to that from the soil (Fig. 5(c)), comprising mainly PP, PES, and small amounts of PE and rayon). Weithmann et al. (2018) found PES, PP, and PE in organic fertilizer. These are also the most commonly used plastics (PlasticsEurope, 2019). The experimental plots, far from residential areas, had a similar composition indirectly indicating that microplastics in the soil were derived from the pig manure.

The average annual abundance of microplastics was $1250 \pm 640$ particles $\mathrm{kg}^{-1}$ in manure (Fig. 5 (d)). The percentage of fibers in pig manure was relatively high (79.2\%). The average input of microplastics from pig manure was estimated to reach $2.11 \pm 1.08$ million particles $\mathrm{ha}^{-1} \mathrm{a}^{-1}$. This is broadly consistent with the calculated average amount of microplastics accumulated in the surface soil. The long-term application of pig manure would have made the dominant contribution to the microplastic abundance of the soil in 

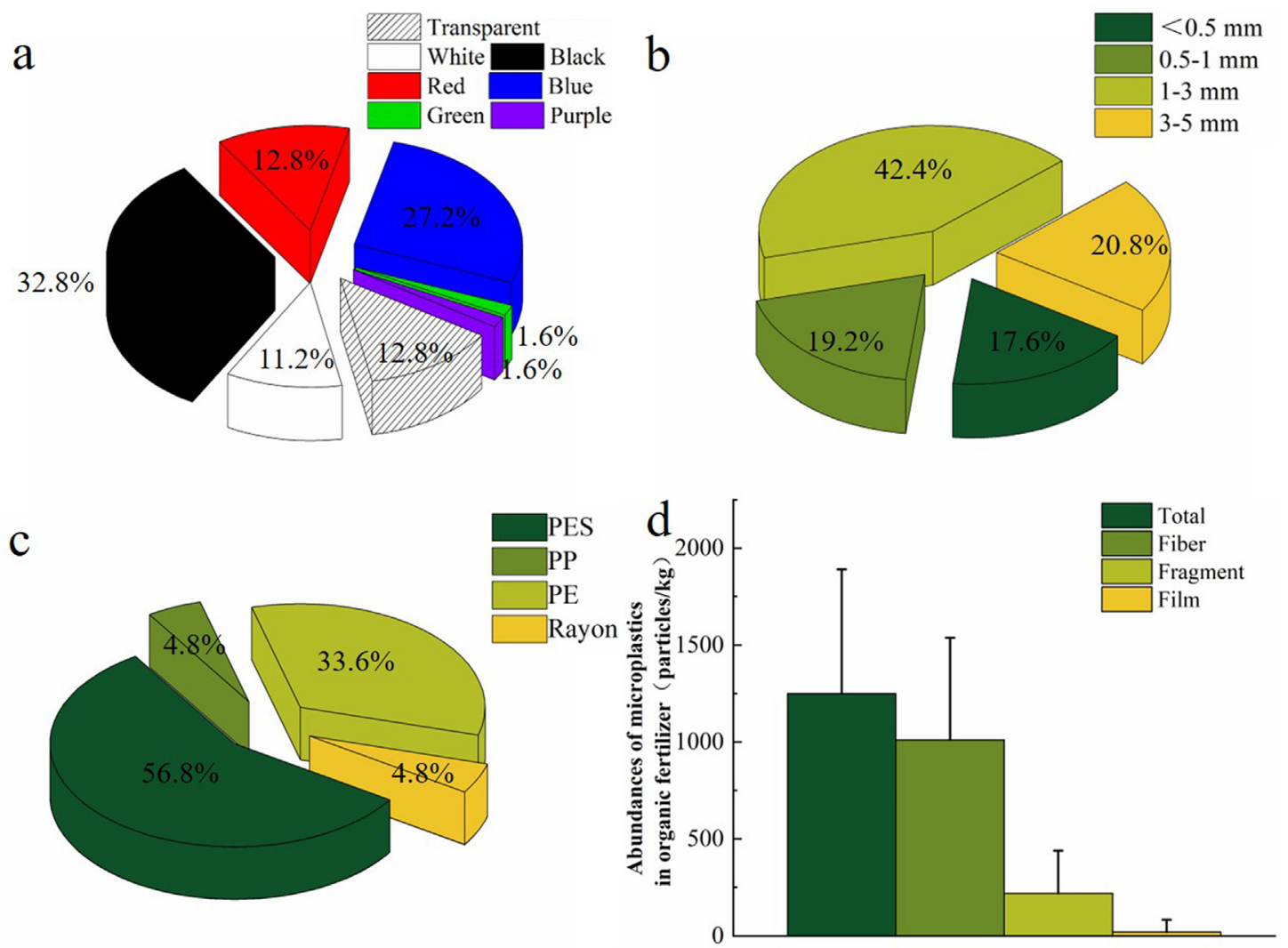

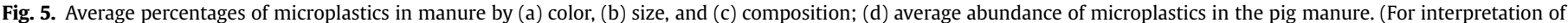
the references to color in this figure legend, the reader is referred to the Web version of this article.)

this area. Weithmann et al. (2018) investigated different organic fertilizers and found that the abundance of microplastics (1-5 mm) in biowaste digestion was $14-895$ particles $\mathrm{kg}^{-1}$. Some of the microplastics in manure may be derived from feces. Liu et al. (2019) reported that microplastics in feces of birds (Poyang Lake, China) reached $4.93 \pm 4.25$ particles $\mathrm{g}^{-1}$. Another investigation of chicken feces found an abundance of microplastics of up to $129.8 \pm 82.3$ particles $\mathrm{g}^{-1}$ (Lwanga et al., 2017). The occurrence of microplastics in feces indicates that they have entered the bodies of animals and humans, possibly from contaminated air, food, and drinking water (Yan et al., 2020). In addition, microplastics are widespread in the air (Enyoh et al., 2019). Exposure to air during composting is another potential source of microplastics in manure. Although fibers and fragments found in pig manure differed in different years (Fig. S5(d) and Fig. S6.), only the fragments in soil receiving repeated applications of sludge showed significant differences from unamended soil. Fibers may more difficult to separate from agricultural soil aggregates than are fragments due to the linear shape of fibers entangling soil aggregates (Zhang et al., 2019b).

\section{Conclusions}

This is the first report showing the distribution of microplastics in soil following long-term repeated application of pig manure. Manure application significantly enriched the soil with microplastics compared with unamended soil. Differences in the color, particle size and consistency of composition suggest that microplastics may break down to form smaller particles when pig manure is applied repeatedly to agricultural land. Moreover, surface morphology indicates that microorganisms may play an important role in the degradation of microplastics. The appearance of oxygen-containing functional groups and clay minerals may result in microplastics more readily adsorbing pollutants and acting as carriers of pollutants. Clearly, the contamination of soils by microplastics via manures is an important topic that merits further investigation.

\section{Author statement}

Jie Yang: Data curation, Methodology, Writing original draft, Visualization, Formal analysis. Ruijie Li: Data curation, Investigation, Methodology. Qian Zhou: Investigation, Methodology. Lianzhen Li: Writing - review \& editing. Yuan Li: Writing - review \& editing. Chen Tu: Writing - review \& editing. Xinyue Zhao: Investigation. Kuanxu Xiong: Software. Peter Christie: Writing review \& editing. Yongming Luo: Conceptualization, Supervision, Writing - review \& editing, Funding acquisition.

\section{Declaration of competing interest}

The authors declare that they have no conflicts of interest.

\section{Acknowledgements}

This research was funded by the National Natural Science Foundation of China (41877142 and 41991330). 


\section{Appendix A. Supplementary data}

Supplementary data to this article can be found online at https://doi.org/10.1016/j.envpol.2020.116028.

\section{References}

Bandow, N., Will, V., Wachtendorf, V., Simon, F., 2017. Contaminant release from aged microplastic. Environ. Chem. 14 (6), 394-405.

Berg, P., Lwanga, E.H., Corradini, F., Geissen, V., 2020. Sewage sludge application as a vehicle for microplastics in eastern Spanish agricultural soils. Environ. Pollut. 261, 114198

Bläsing, M., Amelung, W., 2018. Plastics in soil: analytical methods and possible sources. Sci. Total Environ. 612, 422-435.

Briassoulis, D., Babou, E., Hiskakis, M., Kyrikou, I., 2015. Analysis of long-term degradation behaviour of polyethylene mulching films with pro-oxidants under real cultivation and soil burial conditions. Environ. Sci. Pollut. Res. Int. 22 (4), 2584-2598.

Chen, Y.L., Leng, Y.F., Liu, X.N., Wang, J., 2020. Microplastic pollution in vegetable farmlands of suburb Wuhan, central China. Environ. Pollut. 257, 113449.

Cooper, D.A., Corcoran, P.L., 2010. Effects of mechanical and chemical processes on the degradation of plastic beach debris on the island of Kauai. Hawaii. Mar. Pollut. Bull. 60 (5), 650-654.

Corradini, F., Meza, P., Eguiluz, R., Casado, F., Lwanga, E.H., Geissen, V., 2019. Evidence of microplastic accumulation in agricultural soils from sewage sludge disposal. Sci. Total Environ. 671, 411-420.

Enyoh, C.E., Verla, A.W., Verla, E.N., Ibe, F.C., Amaobi, C.E., 2019. Airborne microplastics: a review study on method for analysis, occurrence, movement and risks. Environ. Monit. Assess. 191, 668.

Fairbrother, A., Hsueh, H., Kim, J.H., Jacobs, D., Perry, L., Goodwin, D., White, C., Watson, S., Sung, L., 2019. Temperature and light intensity effects on photodegradation of high-density polyethylene. Polym. Degrad. Stabil. 165, 153-160.

Feuilloley, P., César, G., Benguigui, L., Grohens, Y., Pillin, I., Bewa, H., Lefaux, S., Jamal, M.J., 2005. Degradation of polyethylene designed for agricultural purposes. Polym. Environ. 13 (4), 349.

Gajst, T., 2016. Analysis of Plastic Residues in Commercial Compost. Nova Gorica. University of Nova Gorica, Slovenia.

Guo, T., Lou, C.L., Zhai, W.W., Tang, X.J., Hashmi, M.Z., Murtaza, R., Li, Y., Liu, X.M., Xu, J.M., 2018. Increased occurrence of heavy metals, antibiotics and resistance genes in surface soil after long-term application of manure. Sci. Total Environ. 635, 995-1003.

Horton, A.A., Walton, A., Spurgeon, D.J., Lahive, E., Svendsen, C., 2017. Microplastics in freshwater and terrestrial environments: evaluating the current understanding to identify the knowledge gaps and future research priorities. Sci. Total Environ. 586, 127-141.

Huang, Y., Liu, Q., Jia, W.Q., Yan, C.R., Wang, J., 2020. Agricultural plastic mulching as a source of microplastics in the terrestrial environment. Environ. Pollut. 260, 114096.

Jian, M.F., Zhou, L.Y., Yu, H.P., Liu, S.L., 2018. Separation and microscopic study of microplastics from the sediments of the wetland in the estuary of Raohe River of Poyang Lake. Acta Scientiae Circumstantiate 38 (2), 579-586.

Karimi, R., Akinremi, W., Flaten, D., 2018. Nitrogen- or phosphorus-based pig manure application rates affect soil test phosphorus and phosphorus loss risk. Nutrient Cycl. Agroecosyst. 111, 217-230.

Li, X.W., Chen, L.B., Mei, Q.Q., Dong, B., Dai, X.H., Ding, G.J., Zeng, E.Y., 2018. Microplastics in sewage sludge from the wastewater treatment plants in China. Water Res. 142, 75-85.

Liu, M.T., Lu, S.B., Song, Y., Lei, L.L., Hu, J.N., Zhou, W.Z., Cao, C.J., Shi, H.H., Yang, X.F., He, D.F., 2018. Microplastic and mesoplastic pollution in farmland soils in suburbs of Shanghai, China. Environ. Pollut. 242, 855-862.
Liu, S.L., Jian, M.F., Zhou, L.Y., Li, W.H., Wu, X.E., Rao, D., 2019. Pollution characteristics of microplastics of migratory birds habitats in wetland of Poyang Lake. Environ. Sci. 6, 1-14.

Luo, Y.M., Zhou, Q., Zhang, H.B., Pan, X.L., Tu, C., Li, L.Z., Yang, J., 2018. Pay attention to research on microplastic pollution in soil for prevention of ecological and food chain risks. Bull. Chin. Acad. Sci. 33 (10), 1021-1030.

Lv, W.W., Zhou, W.Z., Lu, S.B., Huang, W.W., Yuan, Q., Tian, M.L., Lv, W.G., He, D.F., 2019. Microplastic pollution in rice-fish co-culture system: a report of three farmland stations in Shanghai, China. Sci. Total Environ. 652, 1209-1218.

Lwanga, E.H., Gertsen, H., Gooren, H., Peters, P., Salánki, T., van der Ploeg, M., Besseling, E., Koelmans, A.A., Geissen, V., 2016. Microplastics in the terrestrial ecosystem: implications for Lumbricus terrestris (Oligochaeta, lumbricidae). Environ. Sci. Technol. 50, 2685-1672.

Lwanga, E.H., Vega, J.M., Ouej, V.K., Chi, J.A., Cid, L.S., Chi, C., Segura, G.E., Gertsen, H., Salánki, h., Ploeg, M., Koelmans, A.A., Geissen, V., 2017. Field evidence for transfer of plastic debris along a terrestrial food chain. Sci. Rep. 7, 14071.

Ng, E.-L., Lwanga, E.H., Eldridge, S.M., Johnston, P., Hu, H.W., Geissen, V., Chen, D.L. 2018. An overview of microplastic and nanoplastic pollution in agroecosystems. Sci. Total Environ. 627, 1377-1388.

Piehl, S., Leibner, A., Loder, M.G.J., Dris, R., Bogner, C., Laforsch, C., 2018. Identification and quantification of macro- and microplastics on an agricultural farmland. Sci. Rep. 8, 17950.

PlasticsEurope, 2019. Plastics: the Facts 2019. PlasticsEurope, Brussels, Belgium.

Ro, K.S., Novak, J.M., Johnson, M.G., Szogi, A.A., Libra, J.A., Spokas, K.A., Bae, S., 2016. Leachate water quality of soils amended with different swine manure-based amendments. Chemosphere 142, 92-99.

Wang, Q.J., Zhang, Y., Wangjin, X.X., Wang, Y.L., Meng, G.H., Chen, Y.H., 2020. The adsorption behavior of metals in aqueous solution by microplastics effected by UV radiation. J. Environ. Sci. 87, 272-280.

Weithmann, N., Möller, J.N., Löder, M., Piehl, S., Laforsch, C., Freitag, R., 2018. Organic fertilizer as a vehicle for the entry of microplastic into the environment. Sci. Adv. 4 (4), eaap8060.

Xu, B.L., Liu, F., Cryder, Z., Huang, D., Lu, Z.J., He, Y., Wang, H.Z., Lu, Z.M., Brookes, P.C., Tang, C.X., Gan, J., Xu, J.M., 2019. Microplastics in the soil environment: occurrence, risks, interactions and fate - a review. Crit. Rev. Environ. Sci. Technol. $1-48$

Yan, Z.H., Zhao, H.J., Zhu, Q.D., Oiao, R.X., Ren, H.Q., Zhang, Y., 2020. An efficient method for extracting microplastics from feces of different species. J. Hazard Mater. 384, 121489

Zhang, G.S., Liu, Y.F., 2018. The distribution of microplastics in soil aggregate fractions in southwestern China. Sci. Total Environ. 642, 12-20.

Zhang, M.J., Zhao, Y.R., Qin, X., Jia, W.Q., Chai, L.W., Huang, M.K., Huang, Y., 2019a. Microplastics from mulching film is a distinct habitat for bacteria in farmland soil. Sci. Total Environ. 688, 470-478.

Zhang, G.S., Zhang, F.X., Li, X.T., 2019b. Effects of polyester microfibers on soil physical properties: perception from a field and a pot experiment. Sci. Total Environ. 670, 1-7.

Zhang, L.S., Xie, Y.S., Liu, J.Y., Zhong, S., Q Y.J., P, G., 2020. An overlooked entry pathway of microplastics into agricultural soils from application of sludgebased fertilizers. Environ. Sci. Technol. 54 (7), 4248-4255.

Zhou, Q., Zhang, H.B., Fu, C.C., Zhou, Y., Dai, Z.F., Li, Y., Tu, C., Luo, Y.M., 2018. The distribution and morphology of microplastics in coastal soils adjacent to the Bohai Sea and the Yellow Sea. Geoderma 322, 201-208.

Zhou, B.Y., Wang, J.Q., Zhang, H.B., Shi, H.H., Fei, Y.F., Huang, S.Y., Tong, Y.Z., Wen, D.S., Luo, Y.M., Barceló, D., 2020a. Microplastics in agricultural soils on the coastal plain of Hangzhou Bay, east China: multiple sources other than plastic mulching film. J. Hazard Mater. 388, 121814.

Zhou, Q. Tu, C., Fu, C.C., Li, Y., Zhang, H.B., Xiong, K.X., Zhao, X.Y. Li, L.Z., Waniek, J. Luo, Y.M., 2020b. Characteristics and distribution of microplastics in the coastal mangrove sediments of China. Sci. Total Environ. 703, 134807. 